gives support to Pietro Dalpiaz' push for quarkonium spectroscopy at Super-LEAR energies.

In the sessions on rare decays, results on the annihilation into an electron positron pair, and chargeparity violation and the mysteries of the neutral kaon system got plenty of coverage. Here LEAR could play a vital role in testing 1. Inbitious new theoretical ideas, especially with the high intensities expected with ACOL.

In the antiprotons and nuclei session, clear results were presented from exotic atom spectroscopy, from scattering experiments, and evidence has been seen for annihilations of antiprotons both inside and on the surface of nuclei.

In the 'new ideas' sessions, proposals were aired to test the gravitational properties of antimatter, where it is important to check whether antimatter falls down, or whether it 'falls' up! Trapping of extremely low energy (almost stationary) antiprotons in magnetic 'bottles' were discussed, together with very high precision experiments. The idea of studying proton-antiproton atoms produced in flight was aired, and imagination went as far as considering the pro- duction and storage of antihydrogen (an antiproton nucleus with an orbital positron) - which would be the first example of the production of stable neutral antimatter.

The detector session began with a survey by chief detector guru Georges Charpak, who claimed 'the limitations of particle detectors are usually not solely intrinsic but are also determined by the nature of their interaction with the particles, the geometry, and the cost. Very often the advertised limits are illusory'. The unusual physics at LEAR is also acting as fertile ground for detector innovations.

\title{
Science transfer for development
}

\section{by Abdus Salam}

The author, who shared the Nobel Physics Prize in 1979 with Sheldon Glashow and Steven Weinberg, is founder and Director of the International Centre for Theoretical Physics in Trieste, Italy. A native of Pakistan, Abdus Salam has long advocated increased Third World participation in first rate scientific research. The article published here is extracted from a fuller text which first appeared in 'Third World Affairs 1985', published by the Third World Foundation for Social and Economic Studies, London.
Despite the recent realization that science and technology are the sustenance and major hope for economic betterment, the third world (barring a few countries Argentina, Brazil, China, India...) has taken to science - as distinct from technology - as only a marginal activity.

This is also true of the aid-giving agencies of the richer countries, of the agencies of the United $\mathrm{Na}$ tions and also unfortunately of the scientific communities of the developed countries which might naturally have been expected to be the third world scientists' foremost allies.

Policy makers, prestigious commissions (like the Brandt Commission), as well as aid-givers, speak uniformly of problems of technology transfer to the developing countries as if that is all that is involved. Very few within the developing world appear to stress that for long term effectiveness, technology transfers must always be accompanied by science transfers; that the science of today is the technology.

Science transfer is effected by and to communities of scientists. Such communities (in developing countries) need building up to a critical size in their human resources and infrastructure. This building up calls for wise science policies, with long-term commitment, generous patronage, selfgovernance and free international contacts. Further, in our countries. 
the high-level scientist must be allowed to play a role in nationbuilding as an equal partner to the professional planner, the economist and the technologist. Few developing countries have promulgated such policies; few aid agencies have taken it as their mandate to encourage and help with the building up of the scientific infrastructure.

\section{Why Science Transfer?}

First and foremost, we need scientific literacy and science teaching - at all levels - and particularly at the higher levels, for engineers and technologists. This calls for inspiring teachers, and no one can be an inspiring teacher of science unless he has experienced and created at least some modicum of living science during some part of his career. This calls for well-equipped teaching laboratories and (in the present era of fast moving science), the provision of the newest journals and books. This is the minimum scientific infrastructure any country needs.

Next should come demands on their own scientific communities - consisting of their own nationals - from the developing country government agencies and their nascent industries, for discriminatory advice on which technologies would be relevant and worth acquiring.

Still next, for a minority of the developing countries, there is the need for basic scientists to help their applied colleagues' research work. For any society, the problems of its agriculture, of its local pests and diseases, of its local materials base, must be solved locally. One needs an underpinning from a first-class base in basic

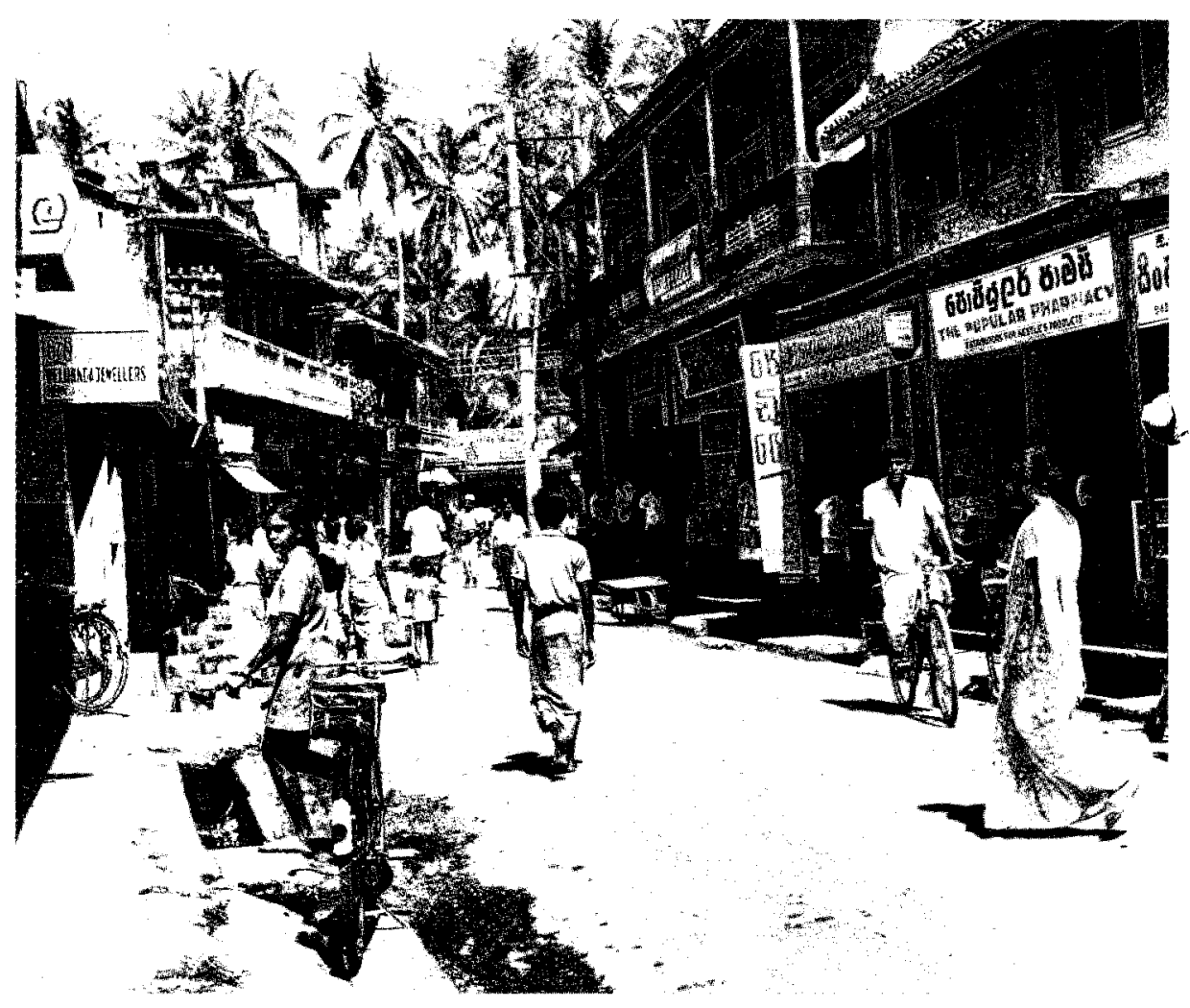

sciences to carry through applied research in these areas. The craft of applied science, in a developing country, is much harder than the craft of basic science, simply because one does not have available expertise.

And finally, at the advanced stages of a country's development, is the need for basic scientific research for the riches it might unexpectedly yield for technology.

Consider some of the breakthroughs in physics. Faraday's unification of electricity and magnetism, accomplished in the last century, is certainly one of the most striking examples. When Faraday was carrying out his experiments - showing that while a stationary electric charge produces an electric force on another charge in its vicinity, a moving electric charge produces a magnetic force - no one could have imagined that this sim- ple discovery would lead eventually to the whole of heavy electrical engineering

Just to emphasise how relativel useless Faraday's work was thought to be by his contemporaries, consider the assessment by one of them, Charles Burney, of electricity versus music. 'Electricity is universally allowed to be a very entertaining and surprising phenomenon, but it has frequently been lamented that it has never yet, with much certainty, been applied to any very useful purpose... (while) it is easy to point out the humane and important purposes to which music has been applied... Many an orphan is cherished by its influence, and the pangs of child-birth are softened and rendered less dangerous...'.

After Faraday came Maxwell, Hertz, ..., leading to the marvels of radio, television and the modern 
communication systems, as well as X-rays.

To see how the climate has changed in developed countries since Faraday's time, when a hundred years after Maxwell, in the 1960s, my colleagues at Harvard, Glashow and Weinberg, and $I$ independently took the next step of postulating a unification of two Warther forces of nature - of electromagnetism with the weak nuclear force of radioactivity - even the London 'Economist' took note and counselled perceptive businessmen not to ignore the likely economic consequences of this new development!

Last year, experiments at CERN provided direct confirmation of our theory. It did so with technical brilliance of the highest order. I am not suggesting that the developing countries should create accelerator laboratories like CERN. However, even if the 'Economist' may have been optimistic in its forecast of direct economic benefits of the new unification of forces, there is no question that these accelerator laboratories are founts of the highest technology in microelectronics, in material sciences, in superconductor as well as vacuum technology. I rejoice that Fermilab in the US has decided to set up a special Institute to make this area of science and related technology available to Latin American physicists. And CERN has made available to us - the Trieste Centre the services of some members of their microprocessor team who have already conducted two sixweek colleges on microprocessor physics and technology at Trieste at the highest level, for 250 of the developing world's physicists. During June 1984, this team held a four week microprocessor col-

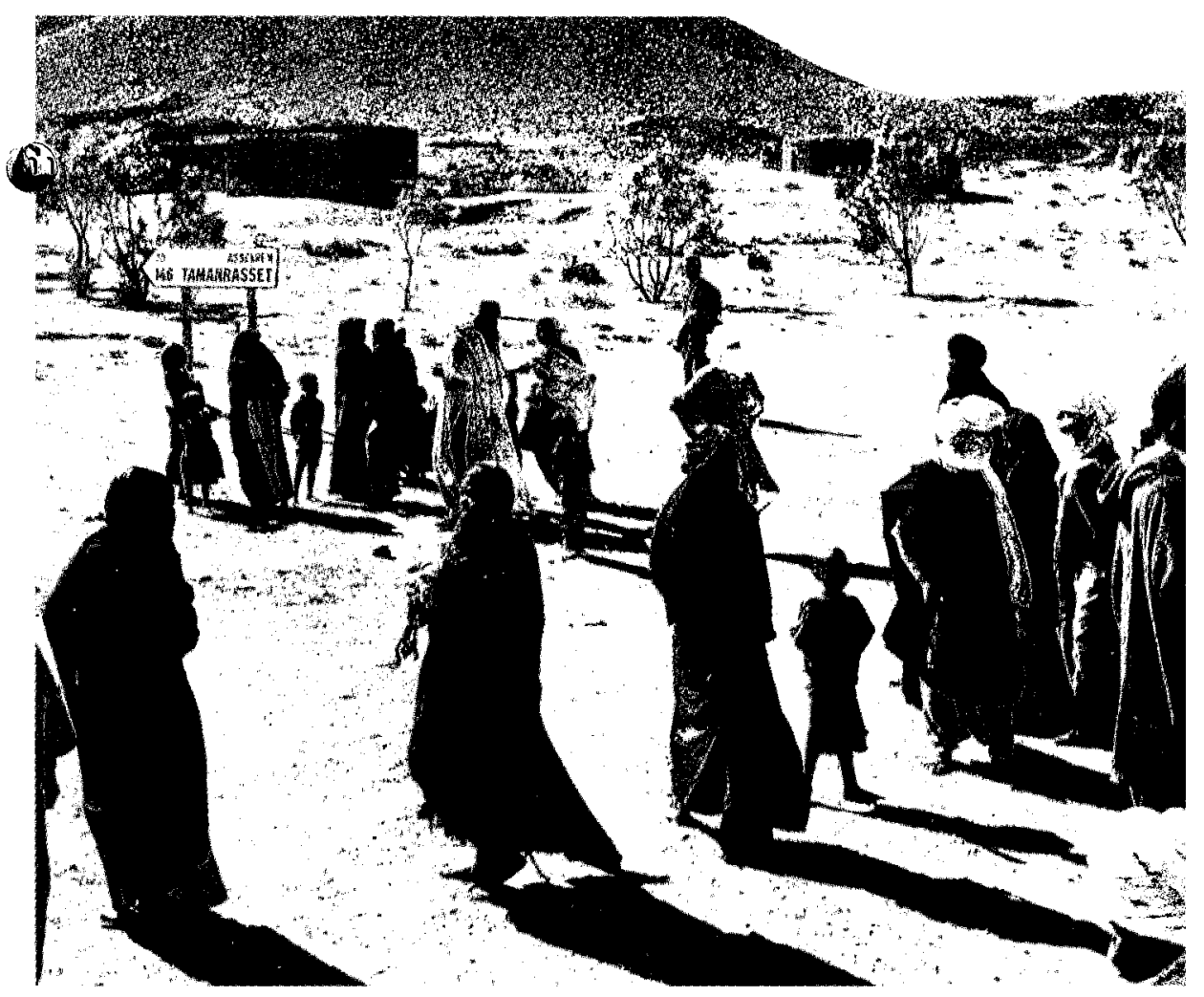

lege in Sri Lanka for 62 physicists from South East Asia; to be followed in the coming years by four week colleges in China, Colombia, Kenya and Morocco.

\section{Science in the Third World}

I can illustrate the situation of scientific research in most of the third world from the example of my own country. In 1951 when I returned to teach in Pakistan after working at Cambridge and Princeton, I could call on just one physicist who had ever worked on a like subject. The most recent issues of 'Physical Review' available were dated before the Second World War. There were no grants whatsoever for attending symposia or conferences; the only time I did attend a conference in the United Kingdom I spent a year's personal savings.

After 30 years, the situation in Pakistan has improved. For a population of around 80 million now, there are some 46 research physicists, experimentalists and theoreticians in Pakistan's 19 universities. (On the US norms these numbers for this population base might have been one hundred-fold larger i.e. five thousand!) These physicists still face the same problems regarding journals, publication dues and attendances at conferences ; Pakistan is still not a member of the International Union of Pure and Applied Physics, since our science administrators do not think we can afford $\$ 1500$ of dues; our physicists are still told that all basic science - even the segments necessary for 'applicable' physics is a frightful luxury for a poor country. However, compared to Pakistan - and a privileged group of some 30 countries - the situ- 
ation in the remaining 60 odd other developing countries is as stark as it was in Pakistan of 1951. First and foremost is the problem of numbers - of a critical size. The total number of research trained physicists in many of these countries can be counted on the fingers of one hand - the choice of subdisciplines in which they may have received training has been conditioned more by chance than design. They make up no communities.

The creation at Trieste of the International Centre for Theoretical Physics in the 1960s came about when some of us from the developing countries urged agencies of the United Nations, and in particular the International Atomic Energy Agency (IAEA) and the United $\mathrm{Na}$ tions Educational, Scientific and Cultural Organization (UNESCO), to assist in ameliorating this situa-

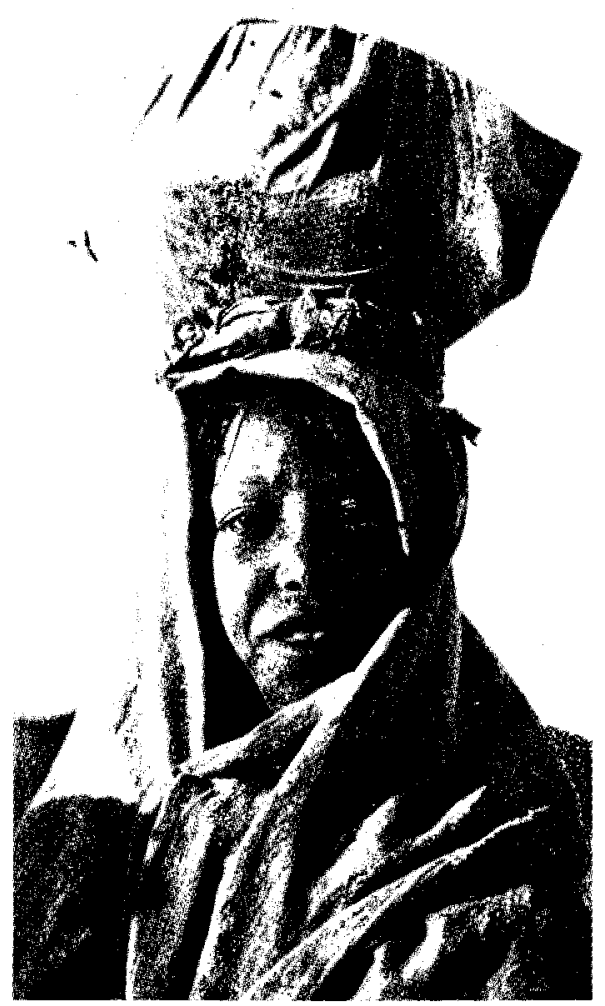

tion regarding theoretical physics research. We met with incomprehension even from some of the developed countries where physics flourishes.

In 1964, four years after the proposal was first mooted and after intense lobbying, the IAEA did agree to create a physics institute. UNESCO joined as equal partner with IAEA in 1970. The Centre has flourished since then, with the support of even those who doubted its validity at first. The bulk of its funds - now amounting to 4.5 million dollars - come from Italy, IAEA and UNESCO. Smaller ad-hoc grants have come from time to time from the United Nations Development Programme (UNDP), the United $\mathrm{Na-}$ tions Financing System for Science and Technology for Development, the United Nations University, the OPEC Fund, the US Department of Energy, the Ford Foundation, the Intergovernmental Bureau for Informatics (IBI), Canada, Kuwait, Libya, Qatar, Sweden, Germany, Sri Lanka, Netherlands, Japan and Denmark. Over the 20 years that the Centre has existed now, it has shifted from emphasis on pure physics towards basic disciplines on the interface of pure and applied physics - disciplines like physics of materials and microprocessors, physics of energy, physics of fusion, physics of reactors, physics of solar and other non-conventional energy, geophysics, biophysics, neurophysics, laser physics, physics of oceans and deserts, and systems analysis - this, in addition to the staples of high energy physics, quantum gravity, cosmology, atomic and nuclear physics and mathematics. Such a shift to the interface of pure and basic applied physics was made simply because there was not and still is

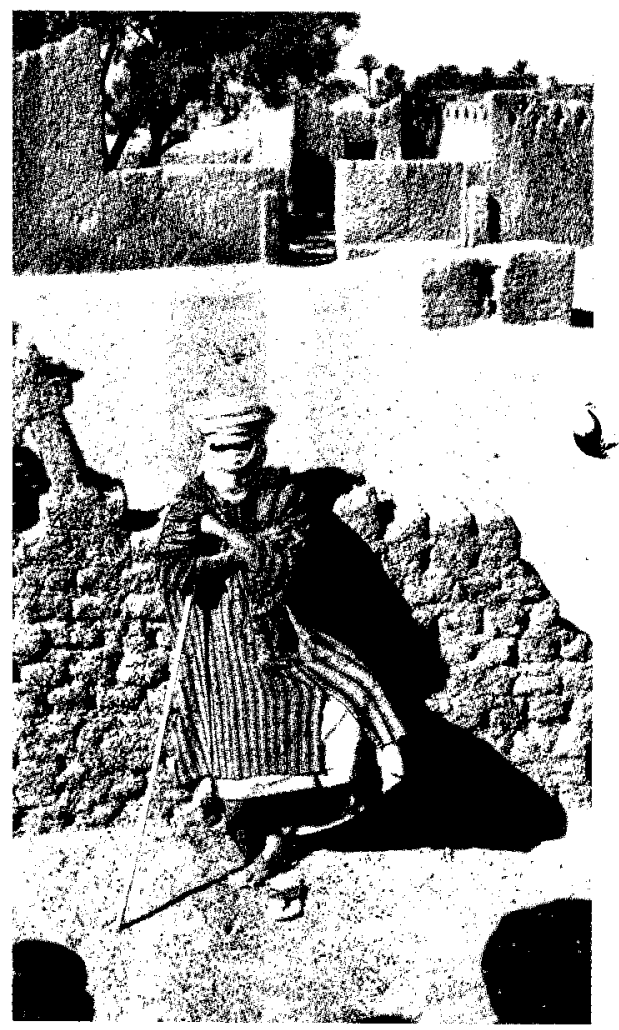

not any other international institute responsive to the scientific hunger of developing country physicists.

Stages and Growth of Sciences in the Third World

Based on the experience gained in physics, we could divide the developing countries (other than Argentina, Brazil, China and India) into three categories. The first category would consist of nine countries - Bangladesh, Korea, Malaysia, Pakistan, Singapore and Turkey in Asia, plus Egypt in Africa and Mexico and Venezuela in Latin America. These countries have a population of physicists, currently approaching criticality, as well as a few centres of high quality for physics where teams of scientists can perform independent research. By and large, these centres are capable of awarding PhD degrees 
for physics within the countries themselves.

In the second category, there would be some 19 countries which consist of Iran, Iraq, Jordan, and Lebanon in the Middle East ; Indonesia, Philippines, Sri Lanka, Thailand and Vietnam in South East Asia; Algeria, Ghana, Kenya, Morocco, Nigeria, Sudan, Tanzania in hifrica; and Chile, Colombia and Peru in Latin America. These countries have a modest population of physicists though at any given university the numbers working are rather small. There are no research groups as such, though in some cases individuals are highly active. As a rule, $\mathrm{PhD}$ degrees are not awarded within the countries concerned. I mention these two categories, because with organized help from the rich world's scientific communities, these countries may take off in a short span of time.

The remaining 60 countries are below the 'poverty line' - some exceptionally bright individuals, whom we elect as associates of he Trieste Centre for the day when active research starts in their countries - but no organized physics research. I stress that these are impressions based on our experience. No other significance should be read into them.

\section{Modalities for Growth of Sciences}

In the end, the growth of science in our countries is our problem. But there is no doubt that outside help - particularly if it is organized - can make a crucial difference. First, regarding the work of individual physicists, this could take various forms: for example, the physical societies of developed countries could help by donating 200-300 copies of their journals to deserving institutions and indi- viduals. They could waive publication and conference charges. In this context, the International Union of Pure and Applied Physics (IUPAP) has helped the Trieste Centre defray postage costs for distribution of old runs of journals; the American Physical Society has helped us with shared subscriptions for 31 physicists from 13 least developed countries.

The research laboratories and the university departments in developed countries could also help by building up links with their opposite numbers and by financing organized visits of their staffs to the institutions in developing countries. They could create schemes like the associateship scheme at the Trieste Centre (whereby a highgrade physicist working in a' developing country becomes part of our staff by being accorded the right to come to us three times in six years), at least for their own exalumni.

Let me now come to the question of the long-term help the United Nations agencies can give in building up scientific infrastructure. I wish to emphasise the role of the modality I am personally most familiar with - international centres of research. There is no question but that the developing world needs today international research institutions, on the applied side, like the Wheat and Rice Research Institute; on the science side, centres like the International Centre for Insect Physiology (ICIPE) in Nairobi. Without internationalization, science cannot flourish; one cannot guarantee standards, guarantee keeping abreast of new ideas, guarantee a continual transfer of science by men who created it and who come to such centres, moved by their idealism.

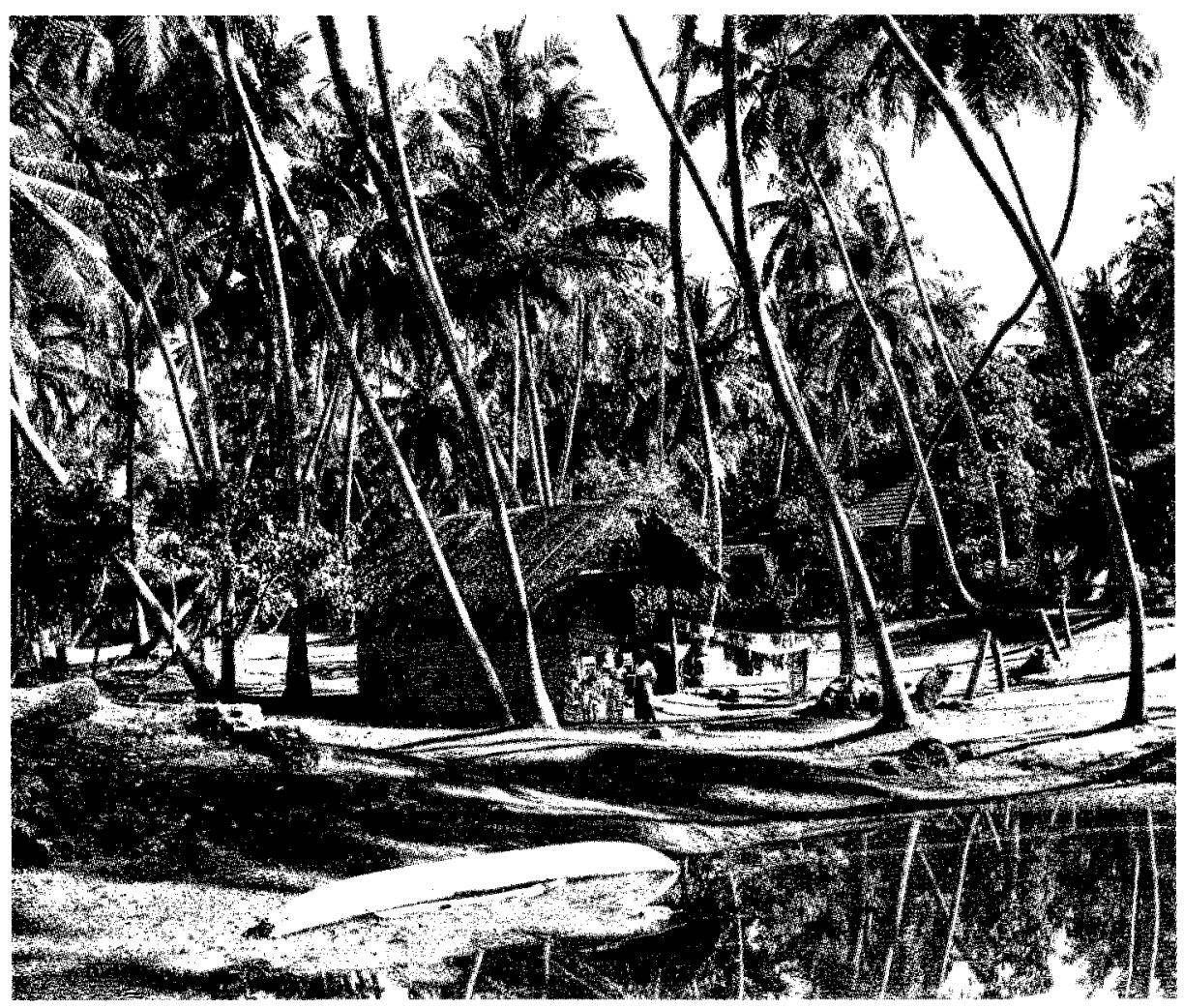


Recently there have been created an international centre of mathematics at Nice, an international science centre in Sri Lanka, one in Turkey and another in Venezuela. An international physics centre, directed towards Latin America, was formally inaugurated in Colombia by its President some months ago. Also the United Nations Industrial Development Organization (UNIDO) is on the way to creating two international centres in the field of biotechnology, one located in Trieste and one in India.

Besides educational planning, besides help with development of scientific agriculture, I would also wish that the World Bank could take it upon itself to emphasise to the developing countries that the fastest route to financial prosperity today lies with areas of science - based on high technology for example, microelectronics, computer software and the like, and that the major investment needed in these areas is investment in creating scientifically highly-literate manpower.

To summarize, my feeling is that almost every developing country has a scientific and technological problem which needs scientific expertise. I strongly feel that the United Nations system must take a lead with this legitimate movement towards internationalization of science within the developing world for the developing world.

In sciences, as in other spheres, this world of ours is divided between the rich and the poor. The richer half - the industrial North and the centrally managed countries, with an income of 5 trillion dollars, spends two per cent of this - more than 100 billion dollars - on non-military science and development research. The remaining half of mankind - the poorer
South, with one fifth of this income of around one trillion dollars spends no more than 2 billion dollars on science and technology. On the percentage norms of the richer countries, they should be spending ten times more - some 20 billions. At the United Nationsrun Vienna Conference on Science and Technology held in 1979 the poorer nations pleaded for international funds to increase their present annual expenditure of 2 billions to 4 billions. They obtained promises, not of two billions, not of one billion, but only one seventh of this. As we know, even this has never been realized and the United Nations Funding System for Science and Technology for Development is without adequate means. Contrast this with the situation in the military sphere. Each nuclear submarine costs 2 billion dollars and there are at least 100

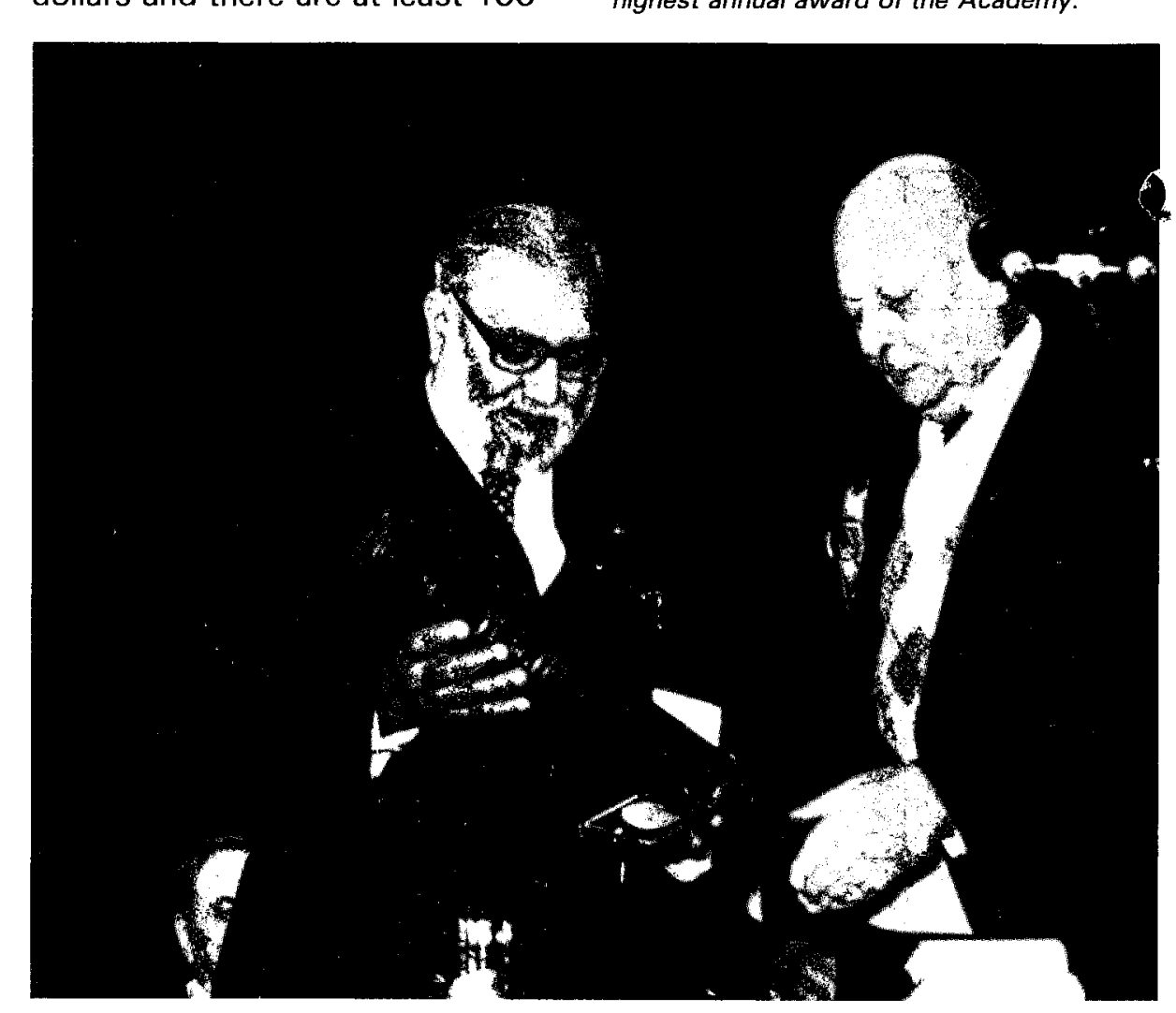

of these in the world's oceans. Five hundred centres like Trieste could be funded for a year for the price of one nuclear submarine.

Let me end by quoting from a great mystic of the 17 th century - John Donne - a man who believed in the moral state of man and the international ideal: 'No man is an island, entire of itself; every man is a piece of the continent, a part of the main; if a clod be washed away by the sea, Europe is the less, as well as if a promontory were, as well as if a manor of thy friends or of thine own were: any man's death diminishes me, because I am involved in mankind; and therefore never send to know for whom the bell tolls; it tolls for thee'.

\section{Last December at the Annual General Assembly of the USSR Academy of Sciences, Abdus Salam was presented with the Lomonosov Gold Medal, the
highest annual award of the Academy}

